\title{
Vivências de estágio supervisionado em Ciências da Natureza em uma escola do campo: reflexão das práticas pedagógicas na formação inicial de professores da Educação do Campo
}

\author{
Andiara dos Santos Araújo ${ }^{1}$, Klayton Santana Porto ${ }^{2}$ \\ ${ }^{1}$ Universidade Federal do Recôncavo da Bahia - UFRB. ${ }^{2}$ Universidade Federal do Recôncavo da Bahia - UFRB, Centro de \\ Ciência e Tecnologia em Energia e Sustentabilidade - CETENS. Avenida Centenário, 697, Bairro SIM. Feira de Santana - BA. \\ Brasil \\ Autor para correspondência/Author for correspondence: klaytonuesb@hotmail.com
}

\begin{abstract}
RESUMO. Neste artigo apresentamos uma análise críticoreflexivo desenvolvida a partir das atividades desenvolvidas no Estágio Supervisionado em Educação do Campo na área de conhecimento de Ciências da Natureza, realizado durante o V semestre do Curso de Licenciatura em Educação do Campo com Habilitação em Ciências da Natureza da Universidade Federal do Recôncavo da Bahia (UFRB). O estágio foi desenvolvido no ano letivo de 2016, no componente curricular Ciências da Natureza, em uma turma do $7^{\circ}$ ano das séries finais do Ensino Fundamental, em uma escola pública do campo de uma comunidade da zona rural situada em um município do interior do estado da Bahia. O objetivo deste artigo foi relatar as experiências vivenciadas no desenvolvimento do estágio supervisionado, como forma de discutir a importância do estágio na formação inicial do professor de Ciências da Natureza da Educação do Campo. O artigo traz descrições das ações realizadas na escola, além de reflexões sobre as metodologias e práticas utilizadas em sala de aula. Desse modo, concluímos que o estágio provê subsídios e conhecimentos imprescindíveis à prática docente, pois este é parte fulcral do nosso processo de formação, sendo este o artifício que nos permite uma interação mais próxima com o cotidiano e as vivências escolares, sobretudo quando tratamos da Educação do Campo.
\end{abstract}

Palavras-chave: Educação do Campo, Ensino de Ciências, Estágio Supervisionado, Formação de Professores.

\begin{tabular}{|l|l|l|l|l|l|l|} 
RBEC & Tocantinópolis/Brasil & v. 4 & e4132 & $10.20873 /$ uft.rbec.v4e4132 & 2019 & ISSN: 2525-4863 \\
\hline
\end{tabular}




\title{
Study supervised in Natural Sciences in a Rural School: reflection of pedagogical practices in the initial training of teachers of the Rural Education
}

\begin{abstract}
In this article we present a critical-reflexive analysis developed from the activities developed in the Supervised Internship in Rural Education in the area of knowledge of Natural Sciences, carried out during the $\mathrm{V}$ semester of the Degree in Rural Education with Qualification in Natural Sciences of the Federal University of the Recôncavo of Bahia (UFRB). The internship was developed in the 2016 school year, in the Nature Sciences curriculum component, in a 7th grade class in the final series of Elementary School, in a rural public school in a rural community located in a municipality in the interior of the state from Bahia. Thus, the objective of this article was to report on the experience of supervised internship development as a way of discussing the importance of the internship in the initial formation of the Rural Science Teacher of Nature. The experiences developed involved individualized learning and training opportunities. These activities took place from participant observations, elaboration of work plan, and pedagogical preparation for the didactic interferences. The article presents descriptions of the actions taken at the school, as well as reflections on the methodologies and practices used in the classroom. In this way, we conclude that the internship provides the necessary subsidies and knowledge to the teaching practice, because this is a central part of our training process, which is the artifice that allows us to interact more closely with daily life and school experiences, especially when dealing with Rural Education.
\end{abstract}

Keywords: Rural Education, Science Teaching, Supervised Internship, Teacher training. 


\section{Vivencias de estadio supervisado en Ciencias de la Naturaleza en una escuela del campo: reflexión de las prácticas pedagógicas en la formación inicial de profesores de la Educación del Campo}

RESUMEN. En este artículo presentamos un análisis críticoreflexivo desarrollado a partir de las actividades desarrolladas en la Etapa Supervisada en Educación del Campo en el área de conocimiento de Ciencias de la Naturaleza, realizado durante el V semestre del Curso de Licenciatura en Educación del Campo con Habilitación en Ciencias de la Naturaleza Universidad Federal de Recôncavo de Bahía (UFRB). La etapa fue desarrollada en el año escolar de 2016, en el componente curricular Ciencias de la Naturaleza, en una clase del $7^{\circ}$ año de las series finales de la Enseñanza Fundamental, en una escuela pública del campo de una comunidad de la zona rural situada en un municipio del interior del estado de Bahía. De este modo, el objetivo de este artículo fue relatar las experiencias vivenciadas en el desarrollo del estadio supervisado, como forma de discutir la importancia del estadio en la formación inicial del profesor de Ciencias de la Naturaleza de la Educación del Campo. Las experiencias desarrolladas involucraron ocasiones individualizadas de aprendizaje y formación. Tales actividades se realizaron a partir de observaciones participantes, elaboración de plan de trabajo, y preparación pedagógica para las interferencias didácticas. El artículo trae descripciones de las acciones realizadas en la escuela, además de reflexiones sobre las metodologías y prácticas utilizadas en el aula. De este modo, concluimos que la práctica provee subsidios y conocimientos imprescindibles a la práctica docente, pues éste es parte central de nuestro proceso de formación, siendo éste el artificio que nos permite una interacción más cercana con el cotidiano y las vivencias escolares, sobre todo cuando tratamos de Educación del Campo.

Palabras clave: Educación del Campo, Enseñanza de Ciencias, Etapa Supervisada, Formación de Profesores. 


\section{Introdução}

De acordo com Caldart (2009, p. 44) "discutir sobre a Educação do Campo hoje, buscando ser fiel aos seus objetivos de origem, exige um olhar de totalidade, em perspectiva, com uma preocupação metodológica, sobre como interpretá-la, combinada a uma preocupação política, de balanço do percurso e de compreensão das tendências de futuro para poder atuar sobre elas". Essa preocupação política envolve os direitos da mulher, do homem, da criança, do jovem e do idoso do campo. Para Arroyo, Caldart e Molina (2004) é de suma importância que a educação abarque o desenvolvimento, levando em consideração os aspectos da diversidade, da situação histórica particular de cada comunidade, seus recursos disponíveis, seus povos, suas expectativas e seus anseios. Para os autores, o currículo das escolas do campo deve ser fundamentado numa lógica de desenvolvimento humano integral, favorecendo a constituição da cidadania e da inclusão social, recolocando os sujeitos do campo no bojo do processo produtivo, com justiça, bem-estar social e econômico.

Desse modo, a formação do professor das escolas do campo deve ser voltada para o contexto da vida dos educandos e da sua realidade social, política, econômica e cultural (Arroyo,
2004). A ênfase dessa prática pedagógica deve ser a busca de um projeto educacional que rompa com os moldes tradicionais de uma educação que não valoriza o trabalho familiar no campo, em regime de economia sustentável e solidária. E neste prisma, o estágio tem um papel crucial na formação destes professores do campo (Caldart, 2004).

O estágio na Educação do Campo configura-se em compreender a questão da Educação do Campo como direito a uma educação de qualidade como "sujeitos de história e de direitos; como sujeitos coletivos de sua formação enquanto sujeitos sociais, culturais, éticos e políticos". (Arroyo, Caldart \& Molina, 2004, p. 11-12). Na Pedagogia da Alternância, o estágio constitui um momento de aprimorar os conhecimentos científicos, teóricos e práticos, que devem ser operacionalizados de modo a fortalecer o diálogo entre as aprendizagens do Tempo Universidade $^{\mathrm{i}}$, as atividades do Tempo Comunidade $^{\text {ii }}$ e a organização do trabalho pedagógico nas escolas do campo e nos espaços não escolares. O estágio, dentro da modalidade da Educação do Campo, permite que o licenciando compreenda a relação entre teoria e prática, promovendo a aproximação da realidade à atividade teórica, cujos espaços educativos são 
permeados por um conhecimento teórico que pensa a natureza da educação ligada ao trabalho, que pondera a heterogeneidade contida nos espaços rurais, contemplando no currículo escolar as peculiaridades de cada local, bem como os saberes ali presentes.

Na Educação do Campo, o debate do campo antecede o da educação ou da pedagogia, ainda que o tempo todo se relacione com ele. De tal forma que, a questão de campo é necessariamente a contestação sobre o trabalho no campo, que está vinculada à extensão da cultura, vinculada às relações sociais e aos processos produtivos da experiência social igualitária no campo, demarcando uma compreensão de educação profissional e da agricultura campesina (Molina, 2004).

Neste sentido, Arroyo (2006) destaca que os movimentos sociais do campo poderão contribuir para dinamizar a escola, cujo intuito da Educação do Campo passa a ser o de oferecer uma educação escolar específica, associada ao conhecimento e à cultura do campo, a fim de desenvolver ações coletivas com a comunidade escolar numa perspectiva de qualificar o processo de ensino e aprendizagem. Sob esta égide, o estágio curricular é compreendido como um método de conhecimento objetivo e prático e que proporciona subsídios para compreender vastos ensinamentos que conduzem ao exercício da sua profissão crucial para a construção dos conhecimentos que se respalda em aproximar o estagiário à sociedade, cuja “dissociação entre teoria e prática resulta em um empobrecimento das práticas nas escolas, o que evidencia a necessidade de explicitar por que o estágio é teoria e prática (e não teoria ou prática)". (Pimenta \& Lima, 2004, p. 41).

Neste artigo, apresentamos uma análise crítico-reflexivo desenvolvida a partir das atividades desenvolvidas no Estágio Supervisionado em Educação do Campo na área de conhecimento de Ciências da Natureza, realizado durante o V semestre do Curso de Licenciatura em Educação do Campo com Habilitação em Ciências da Natureza da Universidade Federal do Recôncavo da Bahia (UFRB). O Estágio Curricular Obrigatório I, cuja discussão é apresentada ao longo deste artigo, teve por objetivo pensar na aprendizagem da profissão docente, promovendo oportunidades formativas, a fim de potencializar conhecimentos, desenvolturas e posicionamentos referentes à profissão docente, considerando a relação direta com o campo de estágio e o desenvolvimento teórico proporcionada pelo curso de licenciatura em Educação do Campo, contribuindo para o processo de formação do professor, construindo 
experiência nas trocas de saberes para a formação de novos profissionais na prática docente.

Ressaltamos que estágio é um meio de conectar o professor, aluno e escola, utilizando a educação como um trabalho colaborativo que gera inúmeras informações indispensáveis para a formação do educador, pois o educando, a partir desta vivência, se torna reflexivo, crítico, analista e mediador, como também, aproxima a teoria da prática de diversas formas cabíveis, para uma prática permeada pela incessante pesquisa, auto avaliação/reflexão, articulando, refletindo e compilando conhecimentos sobre as questões atuais das disposições do trabalho pedagógico, além disso, é uma forma de desenvolver fundamentos teóricos de acordo com o modelo da Educação do Campo e da Questão Agrária.

Sendo assim, é no âmbito escolar que se engendram novos desafios, porém, o estágio é considerado um dos momentos mais significativos para a formação docente. É nesse momento que deparamos com a realidade na qual os licenciandos serão inseridos após a conclusão do curso. O estágio traz consigo três etapas: observação, coparticipação e docência. Nestes momentos, torna-se possível consolidar a importância do conhecimento cientifico, expandindo nossa capacidade de compreender o mundo, de refletir criticamente sobre ele e nele atuar, como também, a oportunidade da convivência com profissionais mais experientes (Pimenta \& Lima, 2011).

O estágio enriquece o progresso de uma formação alicerçada no contexto real na qual possibilita a construção independente do conhecimento cientifico por meio da vivência. Desta forma, "o estágio é o eixo central na formação de professores, pois é através dele que o profissional conhece os aspectos indispensáveis para a formação da construção da identidade e dos saberes do dia a dia”. (Pimenta \& Lima, 2004, p. 56). É indispensável no desenvolvimento da formação do professor licenciado em Educação do Campo com Habilitação em Ciências da Natureza, porque oferece enorme chance de desenvolvimento, estimula a comunicação e o relacionamento interpessoal, como também a aquisição de experiência.

Ressaltamos que o Estágio Curricular Obrigatório I representa um momento importante para os educandos da Licenciatura em Educação do Campo (LEDOC) da UFRB, uma vez que visa preparar os discentes para o efetivo exercício da profissão docente. Desse modo, o objetivo deste artigo foi relatar as experiências vivenciadas no 
desenvolvimento

do

estágio

supervisionado, como forma de discutir a importância do estágio na formação inicial do professor de Ciências da Natureza da Educação do Campo.

Esta pesquisa se justifica, pois, o estágio, enquanto atividade acadêmica, contribui para promover a reflexão acerca da forma como os saberes docentes são adquiridos e aplicados, pois alia conhecimento acadêmico com a experiência vivencial do ambiente de trabalho, visto que esclarece e integra, na prática, os temas abordados nas aulas. Assim sendo, o educando pode aprender melhor o conhecimento sobre a carreira escolhida, por meio da experiência transposta durante o tempo de estágio. Além disso, a formação de professores de Ciências da Natureza da Educação do Campo se funda na prática do ensino, que busca trazer elementos de análise e reflexão para a formação inicial do licenciando, de tal forma que construa visões sobre o ensino de Ciências e aprendizagens baseadas nas experiências pessoais desenvolvidas durante o estágio curricular obrigatório, se constituindo nas percepções e habilidades previamente construídas durante o curso, que, a propósito, caracteriza-se em uma luta dos povos do campo por políticas públicas que garantam o seu direito à educação, que seja no e do campo iii. Formando, deste modo, professores de Ciências que favoreçam o estabelecimento de interações dialógicas professor-aluno, em sala de aula, e preparação do conhecimento científico, a partir dos instrumentos que contribuam para interferir na realidade.

\section{Metodologia}

Para a construção deste artigo foram realizadas pesquisas bibliográficas com abordagens qualitativas e pesquisas documentais nos relatórios e projetos desenvolvidos durante o Estágio Curricular Obrigatório I do curso de Licenciatura em Educação do Campo com Habilitação em Ciências da Natureza.

O estágio foi desenvolvido numa comunidade situada na zona rural de um município do interior do estado da Bahia. Esta comunidade tem peculiaridades e realidade própria, pensando nisso lançamos mão de uma pesquisa de campo, com o intuito de conhecer o público alvo do estágio. De acordo com Gil (2008) a pesquisa de campo busca realizar o aprofundamento acerca de uma realidade específica. É basicamente realizada por meio da observação direta das atividades do grupo estudado e de entrevistas com informantes para captar as explicações e 
interpretações do que ocorre naquela realidade.

A pesquisa procurou focar na coleta das seguintes informações: nome da escola onde o estágio foi realizado, endereço, número de funcionários e professores, número de alunos, área extensiva e quantidade de cômodos da escola, contatos dos professores e direção, quantidade de turmas e respectivas séries; objetivos e missão da instituição escolar. Além da pesquisa de campo, realizamos conjuntamente pesquisas documentais e bibliográficas com abordagem qualitativa, as quais contribuíram para fortalecer os conhecimentos da estagiária quanto à realidade da escola do campo e as principais tendências teóricas que marcam a temática no momento da pesquisa. Os autores mais estudados na pesquisa bibliográfica foram: Caldart (2004), Molina (2004), Arroyo (2004), Fernandes (2004), Leite (1999), Pimenta e Lima (2011).

Como instrumento de coleta de dados, a estagiária utilizou observações, diálogos informais, fotografias e entrevistas com o público alvo do estágio. Desse modo, o estágio teve três momentos metodológicos importantes, assim definidos: observação, coparticipação e docência. Estas três fases foram muito importantes para a plena interação, aprendizagem e desenvoltura da estagiária com sua turma e a professora regente.

Os sujeitos desse estudo foram os alunos do $7^{\circ}$ ano matutino, na disciplina de Ciências, com carga horária semanal de 3 horas, dividida entre três (03) dias semanais, dentre eles as Atividades Complementares (AC), que contribuíram para propiciar o desenvolvimento $\mathrm{e}$ aproximação da realidade, fortalecendo o diálogo entre as aprendizagens do Tempo Universidade e as aprendizagens do Tempo Comunidade. O Estagio Curricular Obrigatório I foi desenvolvido na $\mathrm{V}$ etapa do Curso de Licenciatura em Educação do Campo com Habilitação em Ciências da Natureza, perfazendo um total de 136 horas, repartidas em dois tempos de 68 horas, durante o Tempo Comunidade, e outras 68 horas cumprida anteriormente durante o Tempo Universidade, divididas em Observação participante, coparticipação e docência. Neste período pudemos analisar criticamente a conjuntura educacional $\mathrm{e}$ as bases legais que fundamentam a educação básica.

Como forma de garantir e resguardar os aspectos éticos, o estágio foi formalizado a partir de convênio estabelecido entre universidade e instituição concedente. Foram omitidos dados que pudessem identificar os sujeitos envolvidos na pesquisa, emitindo apenas 
aqueles que tratem da instituição concedente e da estagiária.

\section{Análise crítico-reflexiva do estágio}

O planejamento do estágio foi realizado a partir do Projeto de Aprendizagem do Estágio Supervisionado em Educação do Campo na Área de Ciências da Natureza, que foi elaborado dentro do período de efetivação, após sua produção final foi encaminhada ao professor orientador e, posteriormente, aprovado. Pudemos reunir com o diretor da instituição e com a profissional com formação na área de Ciências (Licenciatura em Biologia), sendo designada a referida professora como a supervisora durante o estágio, para registrar formalmente a consolidação do convênio de estágio.

Após o convênio firmado entre a unidade concedente e a instituição de ensino, foi realizado um encontro com a professora supervisora a fim de obter informações referentes ao plano de unidade do professor regente, este encontro foi o dia " $D$ " das tomadas de decisões, tais como, em qual turma realizar o estágio, qual turno e a apresentação dos conteúdos a serem trabalhados durante as aulas, como também o plano de atividade da estagiária. “A finalidade da organização do trabalho pedagógico deve ser a produção de conhecimentos (não necessariamente original), por meio do trabalho com valor social (não do trabalho do faz de conta, artificial)". (Freitas, 1995, p. 100).

Depois de tudo ser definido iniciamos a prática das seguintes atividades: atividade de observação, coparticipação e docência, sob orientação direta da professora supervisora.

\section{Período de Observação}

Partindo do conceito de observação de acordo com o minidicionário Ediouro da língua portuguesa (2000, p. 670), observação é: 1. Ação ou efeito de observar (-se). 2. Cumprimento fiel (de regra, lei, ordem); observância. 3. Nota, apontamento. 4. Exame minucioso; estudo. Nesta etapa é importante desenvolver atividades de apreensão da realidade da escola (aspectos administrativos, pedagógicos, estruturais, etc.), incluindo ações como diagnóstico e aprendizagem dos alunos, análise crítica do Projeto Político Pedagógico da escola e demais atividades. Portanto, este período, serve para fornecer dados para a elaboração das outras etapas, vínculos com os alunos, escola e professor. Bem, esta fase também é propícia para conhecer o ambiente escolar, como é o funcionamento da instituição na qual se vai trabalhar, a fim 
de assimilar experiência de outros profissionais.

Ao observar a realidade de ensino de Ciências, obtivemos várias impressões acerca desta fase, principalmente quanto à importância da contextualização e da interdisciplinaridade dos conteúdos estudados em sala de aula. Nesta etapa pudemos participar de algumas ações, como diagnóstico de aprendizagem dos alunos, no qual usamos os conhecimentos adquiridos com instrumentos para determinar os fatores influentes em uma determinada situação. Nesse espaço foi possível conhecer os estudantes e suas práticas, realizar observações na reunião de pais e mestres, que, segundo a Lei de Diretrizes e Bases (Brasil, 1996), a educação abrange os processos formativos que se desenvolvem na vida familiar, portanto se faz necessário a presença da família no ambiente escolar. Neste tempo, também fizemos observações nas atividades complementares:

... que é um espaço legitimo para conhecimento e reflexão sobre a realidade da escola e seu contexto, expresso nas observações e registros diários dos/as professores/as sobre a trajetória dos estudantes, assim como nos dados das avaliações internas e externas, desdobrando numa ação pedagógica positiva de mudança/intervenção na escola. É um momento em que a comunidade escolar, em especial as equipes gestoras, coordenadores e docentes se dedicam aos projetos de trabalho que venham contribuir para uma resignificação dos espaços de aprendizagem voltados para a formação integral dos sujeitos, tornando-os ativos, participativos, atuantes e reflexivos. (Aubert, 2008, p. 167).

O educador que pretende obter êxito nos resultados almejados durante sua docência, precisa se manter na posição de observador, pois a partir da observação poderá realizar possíveis ajustes durante o processo de ensino aprendizagem, quebrando a dicotomia teoria/prática. $\mathrm{Na}$ visão de Aragão e Silva (2012, p. 50) a “observação se constitui de uma ação fundamental para análise e compreensão das relações que os sujeitos sociais estabelecem entre si e com o meio em que vivem". Freire (1992, p. 14), corrobora: “observar uma situação pedagógica é olhála, fitá-la, mirá-la, admirá-la, para ser iluminado por ela. Observar uma situação pedagógica não é vigiá-la, mas sim fazer vigília por ela, isto é, estar e permanecer acordado por ela na cumplicidade pedagógica".

A aprendizagem Dialógica se produz nas interações que aumentam o aprendizado instrumental, que favorecem a criação de sentido pessoal e social, que são guiados por princípios de solidariedade e nas quais a igualdade e a diferença são valores compatíveis e mutuamente enriquecedores. (Freire, 1992, p. 23). 
Observamos nesse período outras fases importantes da escola como o préconselho e conselho para elaboração das metas de políticas públicas para promover ações do governo voltadas para atender a necessidade da população, visando equidade, reparação e ampliação de direitos. Essa experiência nos possibilitou desenvolver novos aprendizados, além dos adquiridos na universidade, bem como elaborar maneiras de partilhar a teoria e a prática, nesta busca constante da formação do educador. Pois segundo Freire:

A observação é uma ação altamente reflexiva quando o olhar está pautado para buscar ver o que ainda não sabe. Não é um olhar vago, a espera de descobertas. É um olhar focalizado para detectar, diagnosticar o saber e o não saber do grupo. Por isso mesmo ação estudiosa de realidade pedagógica que, por sua vez, demanda esforço, empenho, disciplina. (2004, p. 43).

Freire descreve deste modo a observação como um exercício crucial para as funções de um educador, dividido em cinco exercícios que, de fato, favorecem a construção do conhecimento. Esses elementos são: a capacidade de silenciar, escutar, olhar, escrever e participar, focando no compromisso com a atividade docente com a turma, o professor, a escola e os funcionários. É a partir deste momento que há a aproximação da realidade com a escola, a fim de compreender os desafios a serem enfrentados nas próximas etapas, pois a execução da prática só se faz possível conhecendo os problemas e planejando, para, desta forma, poder contribuir com o desenvolvimento do educando. De fato, foi uma experiência única, significativa e agradável.

\section{Período de coparticipação}

A coparticipação, de fato, foi um momento de magnificência, devido a ser nesta etapa que as atividades em sala são repartidas entre a professora regente e a estagiária, na qual há uma confiança e interação entre ambos. Também é nessa fase que começamos a interagir com a turma e a auxiliar a professora regente em pequenas ações, nas suas atividades de rotina, como, por exemplo, a elaboração de exercícios e, até mesmo, de materiais avaliativos, ajudando, quando solicitada, na formação de grupos, na supervisão dos mesmos, orientação, chamada no diário de classe, orientações em pesquisas, colaborando com os planejamentos de aulas durante os Acompanhamentos Complementares, na elaboração de atividade para o Projeto de Ciências, participação da gincana promovida pelo projeto, correções de provas/atividades, entre outros pontos. 
A partir deste momento, a estagiária começou a contribuir de forma mais aprofundada com as temáticas e aulas realizadas em sala de aula. Silva $(2005, \mathrm{p}$. 5) afirma que:

no cotidiano acadêmico é perceptível que os graduandos se envolvam com muita disposição e ânimo quando a universidade lhes proporciona a participação em que consigam colocar conhecimentos teóricos em prática, acompanhados de um profissional supervisor ou quando possui uma instituição conveniada que estão em permanente contato com a universidade.

Sendo assim, o papel da estagiária, nesta fase do estágio, foi a de mediar os conhecimentos através da metodologia do 'aprender fazendo', pois para Vieira (1997, p. 76) “a Licenciatura é voltada para a preparação do profissional de ensino fundamental e médio, onde o mesmo elabora e executa os programas adequados aos seus alunos". É uma fase preparatória para a docência da sala.

\section{Período de Docência}

Nesta fase, desenvolvemos ações de regência de classe, sob orientação e supervisão da educadora de estágio, sob orientação direta no momento da regência, acompanhamento e orientações constantes, durante as atividades desenvolvidas ao longo de todo o procedimento.
Dentre as atividades realizadas estão o planejamento de aula, a mediação, acompanhamento e as avaliações das atividades, bem como a sua aplicação, realização de oficina e aula de campo. Pois “compreender a escola em seu cotidiano é condição para qualquer projeto de intervenção, pois o ato de ensinar requer um trabalho especifico e reflexão mais ampla sobre a ação pedagógica que ali se desenvolve". (Pimenta \& Lima, 2009, p. 104).

A metodologia utilizada foi a construção participativa, destacando os mapas conceituais, situações-problema dos temas geradores e sua fundamentação em pesquisas, partindo de ações em sala de aula que contribuíram para promover a aprendizagem de acordo com a realidade contextual da instituição concedente e comunidade local, sendo o projeto "Aqui, nosso lixo é luxo!" um projeto interdisciplinar, estimulando $\quad 0$ conhecimento científico, como também a valorização do conhecimento prévio do educando.

Destacamos para os licenciandos que estão iniciando a docência os impactos das ações/atividades que o estágio traz para a realidade, como um instrumento de orientação para a graduação em licenciatura, com conteúdos específicos que culminam na retomada de conteúdos 
estudados, para a vivência dos conceitos que dialogam com a interdisciplinaridade em práticas educativas, entre teorias e aplicações de produções autônomas em sala de aula.

Para a escola parceira, e para Licenciatura em Educação do Campo acreditamos que as ações desenvolvidas, a partir do estágio, trouxeram para a unidade concedente mais um apoio, no sentido de aproximar a escola básica e a Universidade, com base no diálogo e responsabilidade compartilhada, promovendo oportunidades de construção do conhecimento multidisciplinar, que contribuam para a melhoria do ensino nessas escolas parceiras e a inserção de projetos na formação de professores, nas práticas pedagógicas que fomentam o início e a continuação da docência, em um espaço cada vez mais internacionalizado, mas que traz mudanças que elevam o padrão de qualidade da formação inicial de professores.

Na visão de Pimenta e Lima (2011, p. 61), “o estágio atua como campo de conhecimento e eixo curricular central nos cursos de formação de professores e possibilita que sejam trabalhados aspectos indispensáveis à construção da identidade, dos saberes e das posturas especificas ao exercício profissional docente”. Já para França (2009, p. 168) “o estágio no nível de regência carrega consigo a responsabilidade de oferecer condições para que os futuros professores possam interagir com a situação de ensino e, principalmente, possam apropriar-se de um saber-fazer advindo da experiência coletiva dos professores".

A experiência vivenciada levou a estagiária a conhecer e atuar no cotidiano de uma educadora do campo. Observou, participou, planejou, executou e avaliou os alunos e suas atividades nos diversos momentos do estágio (observação, coparticipação e docência). Durante seu período de estágio na Educação do Campo, a licencianda teve diversas experiências concretas que envolviam alunos, professores e comunidade local. Essas experiências favoreceram a prática das teorias vistas no meio acadêmico, oportunizando mais aprendizado e experiência profissional.

Desse modo, ressaltamos que o Estágio Curricular Obrigatório I, foi um momento que serviu para a estagiária pensar/refletir no seu fazer docente. Possibilitou uma aproximação com a prática do ensinar. Estagiar na realidade dos povos do campo com a Educação do Campo permitiu à licencianda aprimorar seu olhar, instigou o desejo de fazer algo diferente, de fazer a diferença no âmbito escolar, de ampliar os saberes, enquanto professora, partindo de novos saberes reflexivos e libertadores. Pois, como disse Freire (1987, p. 32): 
A pedagogia tem de ser forjada com ele (o oprimido) e não para ele, enquanto homens ou povos, na luta incessante de recuperação de sua humanidade. Pedagogia que faça da opressão e de suas causas objeto da reflexão dos oprimidos, de que resultará o seu engajamento necessário na luta por sua libertação, em que esta pedagogia se fará e refará. (Freire, 1987, p. 32).

Estagiar no campo fez aflorar o entendimento sobre o que realmente é uma educação integral, a qual está intimamente ligada às dimensões física, psíquica, emocional, intelectual, cultural, social e econômica de cada sujeito, comunidade e sua história. Desse modo, a estagiária entendeu que é preciso fazer das atividades não somente um conteúdo a ser aprendido, mas sim uma nova experiência escolar que contribua para a melhor convivência e sobrevivência do sujeito na sua realidade local e abrangente. Ou seja, é preciso ensinar vivenciando as realidades micro e macro dos sujeitos envolvidos no processo de ensino-aprendizagem. Pode-se dizer que o professor vai instigar o aluno a ler o livro e a partir dele também ler seu mundo, ler com os olhos, com o coração, com a consciência crítica, com a vontade de transformar a realidade posta e opressiva.

Portanto, cada etapa trabalhada no estágio não deve ser refletida como um experimento qualquer, mas sim vista como uma experiência de suma importância para a vida do licenciando, pois é através dela que ele estabelece uma conexão com as atividades da sua formação. Desta forma, a estagiária alcançou os objetivos almejados em seu estágio, pois vivenciou na prática as teorias vivenciadas em sala de aula e teve a oportunidade de reafirmar sua opção pela docência. Pois, como afirma Pimenta e Lima (2004) a "relação dos saberes teóricos e saberes práticos durante todo o percurso da formação, garante, inclusive, que os alunos aprimorem sua escolha de ser professor a partir do contato com as realidades de sua profissão".

Pode se afirmar que todos os resultados esperados pela estagiária, sua professora supervisora e seu orientador foram alcançados, visto que a acadêmica obteve um estágio que privilegiou os quatro momentos importantes do processo: investigação e pesquisa documental, observação, coparticipação e regência. Além disso, as atividades planejadas pela regente, a estagiária e o orientador de estágio foram realizadas em sintonia com a realidade e a contextualização territorial, cultural, social e econômica dos alunos.

\section{Considerações finais}

A experiência do estágio é indispensável devido à potencialidade e a importância política, ética e formativa de avançar na aproximação entre as escolas e 
o os estagiários, pois o estágio salienta a importância de contextualizar e explorar, de forma interdisciplinar, os conteúdos estudados, fazendo relação destes conteúdos com a realidade do educando, estimulando-o a pensar e a refletir de forma mais crítica e reflexiva.

Essa educação, comprometida com a participação coletiva, em uma perspectiva que impõe uma educação baseada no saber da comunidade e da realidade do campo, incentiva o diálogo da interação alunoprofessor e das aprendizagens cooperativas, discutindo sobre o sentido da experiência para a prática educativa da Educação do Campo na área de Ciências da Natureza e para a formação profissional.

É necessário desenvolver no contexto escolar relações interpessoais que permitam uma integração das diversas áreas do conhecimento e das diferentes funções de cada membro da escola reconhecendo a necessidade de superação e fragmentação do saber e dos fazeres, característica da escola tradicional. (Brasil, 2006, p. 79).

As três fases exigidas pelo estágio se completam majestosamente, primeiramente observar um novo olhar para a escola e seus hábitos, a segunda participar, compartilhar opiniões e experiências e a terceira ensinar, uma fase gratificante de experiência significativa, que permitiu acentuar o que foi aprendido na teoria.
Uma das conquistas foi poder atuar em uma escola pública do campo e contribuir para a formação dos estudantes de uma forma multidisciplinar, abordando questões educativas para o movimento formativo, que envolveram a escola, como ferramenta de aproximação com as famílias, por meio do uso da Agroecologia, por exemplo, e a participação da comunidade e do envolvimento da estagiária como futura educadora de Ciências da Natureza, para dar assistência nas atividades da escola, utilizando essa experiência do estágio para potencializar a aprendizagem de conteúdos previstos no plano de estudo da escola. Outro ponto positivo foi a colaboração dos alunos e da gestão da escola que nos permitiu enfatizar as expectativas da construção da identidade docente.

Destacamos como desafios: aividades previstas e não realizadas, devido aos distanciamentos entre as proposições dos movimentos sociais do campo e as propostas governamentais para a Educação do Campo e as lacunas das políticas públicas educacionais para essa modalidade de ensino, bem como a administração do tempo, em momentos de observação e coparticipação, em que, em diversos momentos, as aulas ficaram escassas de conteúdos, devido ao 
aceleramento do projeto "aqui, nosso lixo é luxo!”.

Nesse sentido, o estágio supervisionado foi de fundamental importância para a minha formação como educadora do campo da área de Ciências da Natureza, pois propiciou a aproximação da indagação acadêmica ao exercício da sala de aula, permitindo que a licencianda se apropriasse dos saberes intrínsecos à função de educador do campo.

\section{Referências}

Aragão, R. F., \& Silva, N. M. (2012). A Observação como Prática Pedagógica no Ensino de Geografia. Fortaleza: Geosaberes.

Arroyo, M. G., Caldart, R. S., \& Molina, M. C. (2004). Por uma educação do campo. Petrópolis: Vozes.

Caldart, R. S. (2016). Escolas do Campo e Agroecologia: uma agenda de trabalho com a vida e pela a vida. Porto Alegre.

Caldart, R. S. (2009). Educação do Campo: Notas para uma Análise de Percurso. Recuperado de: http://www.scielo.br/pdf/tes/v7n1/03.pdf.

Caldart, R. S. (2002). Por uma Educação do Campo: traços de uma identidade em construção. In Kolling, E. J. (Org.). Educação do Campo: identidade e políticas públicas. (4). Brasília: Art. Nacional Por Uma Educação do Campo.

Caldart, R. S. (2004). Por uma educação do campo: traços de uma identidade em construção. In Arroyo, M., Caldart, R. S.,
\& Molina, M. C. (Orgs.). Por uma Educação do Campo (pp. 25-36). Petropólis: Vozes.

Freire, P. (2005). Pedagogia da Autonomia: saberes necessários a prática educativa. São Paulo: Paz e Terra.

Freire, P. (1987). Pedagogia do Oprimido. Rio de Janeiro: Paz e Terra.

Freire, M. (2004). O olhar do observador. Recuperado de: http://anamariacoord.blogspot.com.br/2004 /06/o-olhar-do-observador.html 2004.

Freire, P., \& Freire, M. (1992). Observação, Registro, Reflexão: Instrumento Metodológico. Série Seminários. São Paulo: Espaço Pedagógico.

Freitas, L. C. (1995). Crítica da organização do trabalho pedagógica e da didática. Campinas, SP: Papirus.

França, D. S. (2009). Formação do pedagogo: a orientação dos estágios de ensino pelo professor da escola básica. In IX Congresso Nacional de Educação EDICERE. III Encontro Sul Brasileiro de Psicopedagogia, 26 a 29 de outubro de 2009.

Flecha R. (2017). Comunidade de Aprendizagem. Recuperado de: http://www.comunidadedeaprendizagem.c om. Acesso em: 03 de agosto de 2017.

Gil, A. C. (2002). Como elaborar projetos de pesquisa. São Paulo: Atlas.

Lima, M. S. L. (2012). Estágio $e$ aprendizagem da profissão docente. Brasília: Liber Livro.

Leite, S. C. (1999). Escola rural: urbanização e políticas educacionais. São Paulo: Cortez. 
Pimenta, S. G. (2005). Saberes pedagógicos e atividade docente. São Paulo: Cortez.

Pimenta, S. G., \& Lima, M. S. L. (2004). Estágio e Docência. São Paulo: Cortez, 2004.

Pires, A. M. M. (2009). A educação do campo como direito a uma escola pública de qualidade - SEDUC-PE. Recuperado de:

http://www.anpae.org.br/congressos_antig os/simposio2009/38.pdf.

Resolução $\mathrm{n}^{\circ}$ 017/2016 do curso de Licenciatura em Educação do Campo com habilitação em Ciências da Natureza e Matemática da Universidade Federal do Recôncavo da Bahia - UFRB. (2016). Recuperado de: https://ufrb.edu.br/soc/components/com_ch ronoforms5/chronoforms/uploads/documen to/20161005154443_017_2016_conac.PD F.

Seta, A., Garcia, C., \& Flecha, R., \& Racionero, S. (2008). Recuperado de: http://www.comunidadedeaprendizagem.c om/aprendizagem-dialogica.

Silva, S. A. P. S. (2005) Estágios Curriculares na Formação de Professores de Educação Física: o Ideal, o Real e o Possível. Revista Digital, 10(82), 3-5.

\footnotetext{
${ }^{\mathrm{i}}$ Termo designado para indicar o tempo em que as atividades pedagógicas são desenvolvidas no ambiente universitário.

ii Termo designado para indicar o tempo de desenvolvimento das atividades pedagógicas nos territórios das comunidades do campo.

iii Segundo Caldart (2004, p. 149-150): “no: o povo tem direito a ser educado onde vive; do: o povo tem direito a uma educação pensada desde o seu lugar e com a sua participação, vinculada a sua cultura e às suas necessidades humanas e sociais".
}

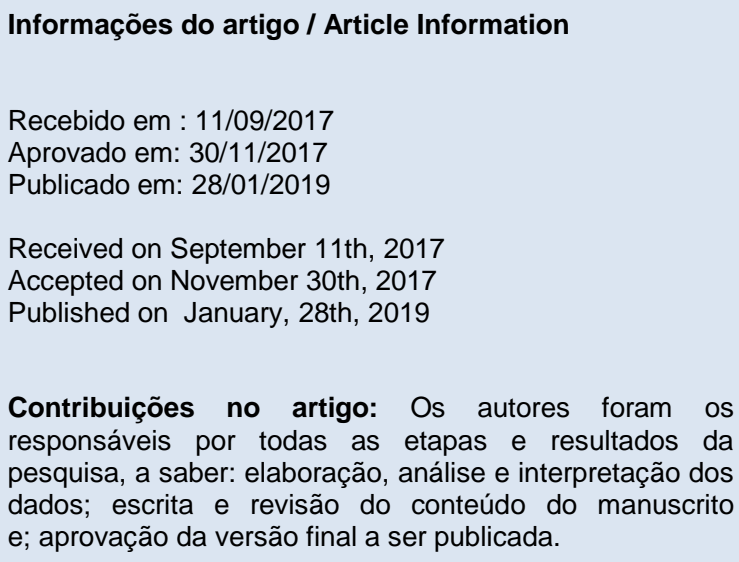
pesquisa, a saber: elaboração, análise e interpretação dos dados; escrita e revisão do conteúdo do manuscrito e; aprovação da versão final a ser publicada.

Author Contributions: The authors were responsible for the designing, delineating, analyzing and interpreting the data, production of the manuscript, critical revision of the content and approval of the final version to be published.

Conflitos de interesse: Os autores declararam não haver nenhum conflito de interesse referente a este artigo.

Conflict of Interest: None reported.

Orcid

Andiara dos Santos Araújo

iD http://orcid.org/0000-0001-8525-2255

Klayton Santana Porto

http://orcid.org/0000-0003-4024-6737

\section{Como citar este artigo / How to cite this article}

APA

Araújo, A. S., \& Porto, K. S. (2019). Vivências de estágio supervisionado em Ciências da Natureza em uma escola do campo: reflexão das práticas pedagógicas na formação inicial de professores da Educação do Campo. Rev. Bras. Educ. Camp., 4 e4132. DOI: http://dx.doi.org/10.20873/uft.rbec.e4132

\section{ABNT}

ARAÚJO, A. S.; PORTO, K. S. Vivências de estágio supervisionado em Ciências da Natureza em uma escola do campo: reflexão das práticas pedagógicas na formação inicial de professores da Educação do Campo. Rev. Bras. Educ. Camp., Tocantinópolis, v. 4, e4132, 2019. DOI: http://dx.doi.org/10.20873/uft.rbec.e4132 